\title{
Inflammation and repeated infections in CGD: two sides of a coin
}

\author{
Taco Kuijpers • Rene Lutter
}

Received: 13 September 2011/Revised: 13 September 2011/Accepted: 13 September 2011/Published online: 15 November 2011 (C) The Author(s) 2011. This article is published with open access at Springerlink.com

\begin{abstract}
Chronic granulomatous disease (CGD) is an uncommon congenital immunodeficiency seen approximately in 1 of 250,000 individuals. It is caused by a profound defect in a burst of oxygen consumption that normally accompanies phagocytosis in all myeloid cells (neutrophils, eosinophils, monocytes, and macrophages). This "respiratory burst" involves the catalytic conversion of molecular oxygen to the oxygen free-radical superoxide, which in turn gives rise to hydrogen peroxide, hypochlorous acid, and hydroxyl radicals. These oxygen derivatives play a critical role in the killing of pathogenic bacteria and fungi. As a result of the failure to activate the respiratory burst in their phagocytes, the majority of CGD patients suffer from severe recurrent infections and rather unexplained prolonged inflammatory reactions that may result in granulomatous lesions. Both may cause severe organ dysfunction depending on the tissues involved. Preventive measures as well as rapid (invasive) diagnostic procedures
\end{abstract}

T. Kuijpers $(\bowtie)$

Emma Children's Hospital, Academic Medical Center (AMC),

University of Amsterdam, Room H7-230, Meibergdreef 9,

1105 AZ Amsterdam, The Netherlands

e-mail: t.w.kuijpers@amc.uva.nl

T. Kuijpers

Sanquin Research and Landsteiner Laboratory AMC, Department of Blood Cell Research,

University of Amsterdam, Amsterdam, The Netherlands

R. Lutter

AMC, Department of Experimental Immunology,

University of Amsterdam, Amsterdam, The Netherlands

R. Lutter

AMC, Department of Respiratory Medicine,

University of Amsterdam, Amsterdam, The Netherlands are required to successfully treat CGD. Hematopoietic stem cell transplantation may be a serious option in some of the patients.

Keywords Infection - Inflammation - Granuloma · NADPH oxidase · IDO - Tryptophan - Kynurenine · IL-17 · Tregs

\section{Background}

Chronic granulomatous disease (CGD) is a rare genetic disorder caused by a defective NADPH oxidase enzyme complex [1,2]. This complex enzyme is responsible for the burst of oxygen consumption (respiratory burst), which is associated with phagocytosis by professional phagocytes, i.e., neutrophils, eosinophils, monocytes, and macrophages. The enzyme reduces oxygen, giving rise to superoxide $\left(\mathrm{O}_{2}{ }^{-}\right)$and subsequent reactive oxygen species, which contribute to the killing of phagocytized microorganisms.

In the majority of CGD patients, the defective NADPH oxidase is responsible for an inadequate anti-microbial response, particularly to fungi, yeasts, and several bacterial species such as Staphylococcus species, Gram-negative bacteria such as Escherichia coli, nontyphoid Salmonella species, Klebsiella pneumoniae, and more rare species such as Burkholderia cepacia or actinomycosis species like Nocardia asteroids $[2,3]$.

The organs affected most are the lungs, skin, gastrointestinal tract, lymph nodes, and the liver. Pneumonia is a major complication that occurs, followed by lymphadenitis, infectious dermatitis, and the formation of abscesses. Although this points to underlying microbial infections, surprisingly, at most clinical episodes, no causative pathogen can be isolated. 
The formation of granulomas is the other key feature in CGD, hence its name chronic granulomatous disease [1-3]. Granulomas are highly dynamic structures that, at least initially, center on the micro-organism or cells containing the intracellular micro-organism and at its border consist of a cellular barrier [4]. The formation of granuloma is particularly manifest in conditions with an inadequate antimicrobial defense, which may relate to the causative pathogen and/or to the condition of the host. In that respect, granuloma may be viewed as a means to contain persisting microorganisms and to seclude these from the host's immune response. In CGD, the granulomas found are often sterile, indicating that the presence of granuloma does not appear to require the continued presence of microorganisms.

The granulomatous lesions can manifest themselves as obstruction in the gut, urinary tract, or pulmonary tree, but also result in a bleeding colitis with a clear failure to thrive.

These two clinical manifestations, infection and inflammation, make the disease difficult to treat. Early diagnosis is beneficial to the patient because of prophylactic measures, but also when a disease episodes is at stake, early diagnostic procedures must be entertained to have a clue on what to do in clinical terms.

\section{Genetics}

The clinical presentation of CGD varies between patients, ranging from early to late in life and from mild to fatal [3]. At least some of this variation in presentation appears to be related to the underlying genetic defect. Mutations have been described for five subunits of the NADPH oxidase, i.e., gp $91^{\text {phox }}, \mathrm{p} 47^{\text {phox }}$, and much more seldom in $\mathrm{p} 67^{\text {phox }}$, $\mathrm{p} 22^{\text {phox }}$, and $\mathrm{p} 40^{\text {phox }}[2,3,5]$.

$C Y B B$, the gene encoding the large gp91 ${ }^{\text {phox }}$ subunit of the transmembrane component cytochrome b558 of the NADPH oxidase complex, is localized on the X-chromosome. Genetic defects in $C Y B B$ are responsible for the majority of patients, most often affecting males. All other mutations are autosomal, which appear associated with a milder presentation as reflected by a higher median age at death and mean survival time and found among males and females equally $[1,5]$.

\section{Biochemistry}

A number of molecular processes involved in NADPH oxidase activation and regulation are known in some detail [1] and the current working model is schematically shown in Fig. 1. The catalytic core of NADPH oxidase consists of cytochrome $b_{558}$, a heterodimeric membrane protein with subunits gp91 ${ }^{\text {phox }}$ and $\mathrm{p} 22^{\text {phox }}$. The gp91 ${ }^{\text {phox }}$ subunit (also

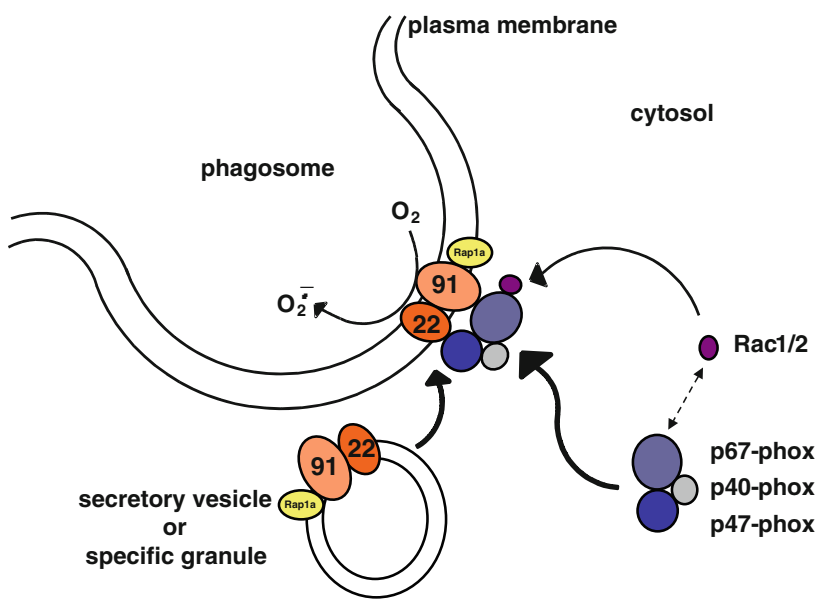

Fig. 1 NADPH oxidase enzyme complex in neutrophils. Upon cellular activation, an active enzyme complex of proteins is formed, consisting of the membrane-associated cytochrome b558 and the cytosolic components $\mathrm{p} 40^{\text {phox }}, \mathrm{p} 47^{\text {phox }}, \mathrm{p} 67^{\text {phox }}$. The enzymatic activity of this protein complex-and only as a complex-is able to generate large amounts of superoxide

called Nox2) is a flavohemoprotein containing all the catalytically active prosthetic groups. The small subunit $\mathrm{p} 22^{\text {phox }}$ is a stabilizing protein for gp91 ${ }^{\text {phox }}$ and a docking site for cytosolic proteins that are indispensable for in vivo NADPH oxidase activation. The architecture of the NADPH oxidase (i.e., the separation between membranebound and cytosolic subunits) allows its activity to be tightly regulated.

Regulation is crucial, since accidental or excessive production of ROS may lead to, for example, inflammatory tissue injury, carcinogenesis, and atherosclerosis. Several regulatory pathways exist in the onset and shutdown of NADPH oxidase activity, involving different intracellular signaling cascades. Phosphorylation of the cytosolic subunits $\mathrm{p} 47^{\text {phox }}, \mathrm{p} 67^{\text {phox }}$, and $\mathrm{p} 40^{\text {phox }}$ by protein kinases and the generation of lipid second messengers such as arachidonic acid, phosphatidic acid, and diacylglycerol by phospholipases are the two most important signaling mechanisms in this respect. Additionally, the small GTPase Rac 2 also has a profound influence on the assembly of a functional NADPH oxidase in neutrophils, since a mutation in the GTP-binding site of Rac2 (as found in a patient) [6] results in a lack of NADPH oxidase activity. However, the exact role Rac2 plays in activation and regulation is still under debate [7].

\section{Pathophysiology of CGD}

The molecular defects in CGD are known, but how this leads to the resulting pathophysiology is not well understood. The key features in the pathophysiology of CGD are 
the exaggerated inflammatory responses and the formation of granuloma. The exaggerated inflammatory responses in CGD may in part be explained by insufficient clearance of the causative microorganisms. Frequently though, inflamed sites are sterile, indicating that this microbial persistence may not be the only explanation. The first experimental data indicative of an exaggerated inflammatory response in CGD independent of an infectious agent came from a study in patients [8], clinical observations, and subsequently supported by experimental animal studies using gp91 ${ }^{\text {phox }}$ and $\mathrm{p} 47^{\text {phox }}$ knock-out mice $[9,10]$.

The hyperinflammatory reactivity of the host immune system was extended in in vitro studies showing that CGD phagocytes display exaggerated inflammatory mediator responses to various stimuli [11-13]. The absence of ROS in CGD phagocytes resulted in exaggerated TNF- $\alpha$ production [13] and inflammasome activity which-under certain conditions - may be held responsible for the IL- $1 \beta$ production in CGD [14-16].

\section{Granuloma formation and immune reactivity}

Recent studies have brought more insight into the structure of granuloma, even though the involvement of the various cell types in a granuloma may differ between tissues and among diseases.

Expression of the enzyme indoleamine 2,3-dioxygenase (IDO) at the border of granulomata is a common feature [17]. IDO, at the expense of superoxide, degrades the amino acid L-tryptophan to L-kynurenine, which is catabolized further (Fig. 2) [18].

L-tryptophan is an essential amino acid for most microbial pathogens, and thus its depletion halts bacterial growth and viral replication $[19,20]$. In addition, low concentrations of L-tryptophan and enhanced concentrations of L-kynurenine and some of its metabolites halt cellcycle progression and promote apoptosis of $\mathrm{T}$ lymphocytes, thereby diminishing the initiation of an immune response $[21,22]$. Therefore, IDO expression in granulomata may halt bacterial growth and dampen $\mathrm{T}$ cell responses towards the causative pathogen.

Interferon- $\gamma($ IFN- $\gamma)$ is the primary inducer of IDO expression. TNF- $\alpha$ released upon infection by dendritic cells and macrophages is able to induce the IFN- $\gamma$ that in its turn can induce IDO activity in granuloma [17].

\section{Indoleamine 2,3-dioxygenase and CGD}

Aspergillus infection has recently been studied in a CGD mouse model, and activity of IDO was shown to be crucial for the survival of Aspergillus infection [23]. IDO converts

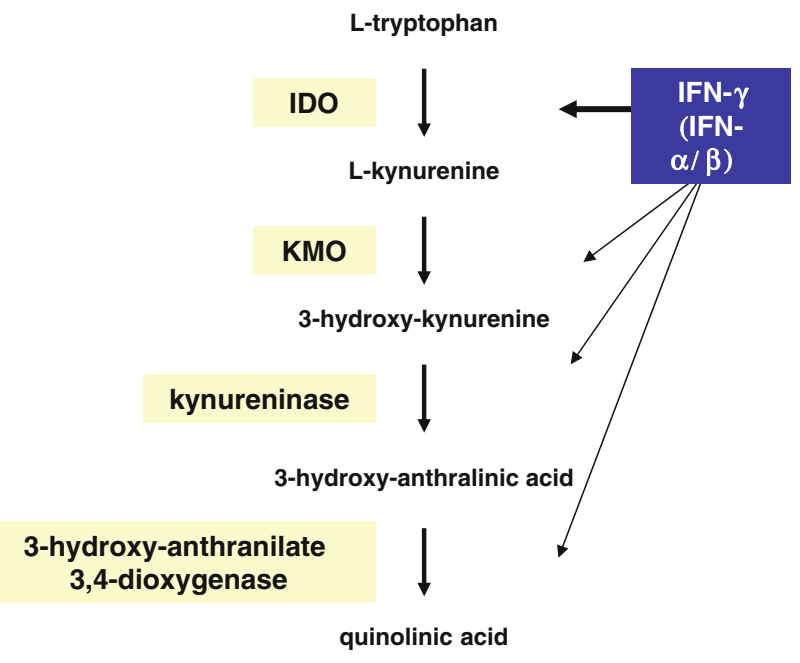

Fig. 2 Interferon-induced tryptophan catabolism via IDO. Interferon- $\gamma$ is a major inducer of IDO expression and possibly of other enzymes involved in the catabolism of tryptophan, the kynurenine pathway. IDO is the rate-limiting enzyme in the kynurenine pathway; hence, regulating IDO-dependent counter-inflammatory homeostatic responses in potentially harmful inflammation, and requires superoxide for its activity. Tryptophan catabolism leads to tryptophan starvation and the production of immunoregulatory kynurenine metabolites, the combined effects of which result in an arrest of lymphocyte proliferation, induction of apoptosis and reversible impairment of $\mathrm{T}$ cell activity, as well as in the induction of various mediators, such as IL-6, IL-8, and IL-10

L-tryptophan into L-kynurenine but requires superoxide as a cofactor for its activity. Secreted L-kynurenine subsequently acts as an anti-inflammatory agent, by mechanisms that are not completely understood but have been shown to induce cell death in pro-inflammatory $\gamma \delta \mathrm{T}$ cell subsets producing IL-17 [23]. Romani et al. thus concluded that hyperinflammation caused a lethal outcome for CGD mice upon challenge with Aspergillus, rather than a defective clearance itself, as was previously suggested in CGD patients with an overwhelming pulmonary aspergillosis [24]. This seems plausible in view of a large body of evidence showing that CGD patients often display exaggerated immune responses against immunologic challenges [13], and granulomas have been shown to develop in the absence of any detectable pathogen, even after wound sterilization or after injection of heat-inactivated pathogens [9].

Romani and coworkers underscore their conclusion by demonstrating that CGD mice, which all died upon Aspergillus challenge, survive this infection when treated with the IDO product L-kynurenine in combination with IFN- $\gamma$. In turn, wild-type mice, which normally survive this challenge, no longer overcome Aspergillus infection when treated with the IDO-inhibitor 1-MT [23]. Although the specificity of the challenge and the background of the CGD 
mouse strain are subject for debate, the above-mentioned relevant findings have certainly opened a field of research at the boundary of innate and adaptive immunity and the complex interplay between the two defense systems.

There are a number of experimental findings that also contrast with those reported by Romani's group. First of all, Murray et al. [25] showed that IFN- $\gamma$-exposed monocytes and monocyte-derived macrophages from a CGD patient degraded tryptophan just like cells from a healthy individual. This suggests that superoxide from the NADPH oxidase is not the essential cofactor for IDO activity. In fact, there are several studies that suggest that IDO may acquire its reducing equivalents from prosthetic groups such as heme and flavin [26, 27], unrelated to the NADPH oxidase enzyme.

Another major aspect of the study by Romani et al. is that L-kynurenine is not accumulating in CGD mice and L-kynurenine suppletion restores the defective down-regulation of the inflammatory $\gamma \delta \mathrm{T}$ cells. IDO is the ratelimiting enzyme in the kynurenine cascade, meaning that the IDO-generated L-kynurenine is usually very quickly catabolized. Thus, an alternative explanation for the findings by Romani et al. could be that L-kynurenine is more rapidly degraded in CGD patients than in healthy individuals. If so, the lack of L-kynurenine can not be taken as a measure of defective IDO activity. In a CGD cohort study, these issues were addressed most recently by the group of Malech, who demonstrated that IFN- $\gamma$ induces normal levels of L-kynurenine in cultures of monocytes, dendritic cells, and PMN from gp $91^{\text {phox }}$ and $\mathrm{p} 47^{\text {phox }}$-deficient human CGD patients. L-kynurenine accumulation was dose- and time-dependent, as was that of the downstream metabolite 3-OH anthranilic acid. Furthermore, urinary and serum levels of L-kynurenine and a variety of other tryptophan metabolites were elevated rather than suppressed in CGD donors [28].

As explicitly stated, the data in CGD patients only demonstrated the lack of abnormal IDO activity in blood cells, but little is known about tissue activity or localization. In preliminary immunohistochemical studies, a marked expression of IDO was noticed at the rim of granulomata in lung tissue from CGD patients (Fig. 3). Infection was excluded in these pathological patient-derived tissue samples. Neutrophils were found predominantly in the center of the granulomata, $\mathrm{T}$ cells both in the center and outside of the granulomata, whereas macrophages particularly localized at the border of the granulomata. These macrophages expressed most if not all of the IDO protein detected in these tissue samples. In particular, the neutrophils showed virtually no IDO protein expression, in contrast to the findings in the mouse model as reported by Romani et al. [23].

It was noted that the IDO expression in CGD tissue is much more abundant than that in granulomatous tissue
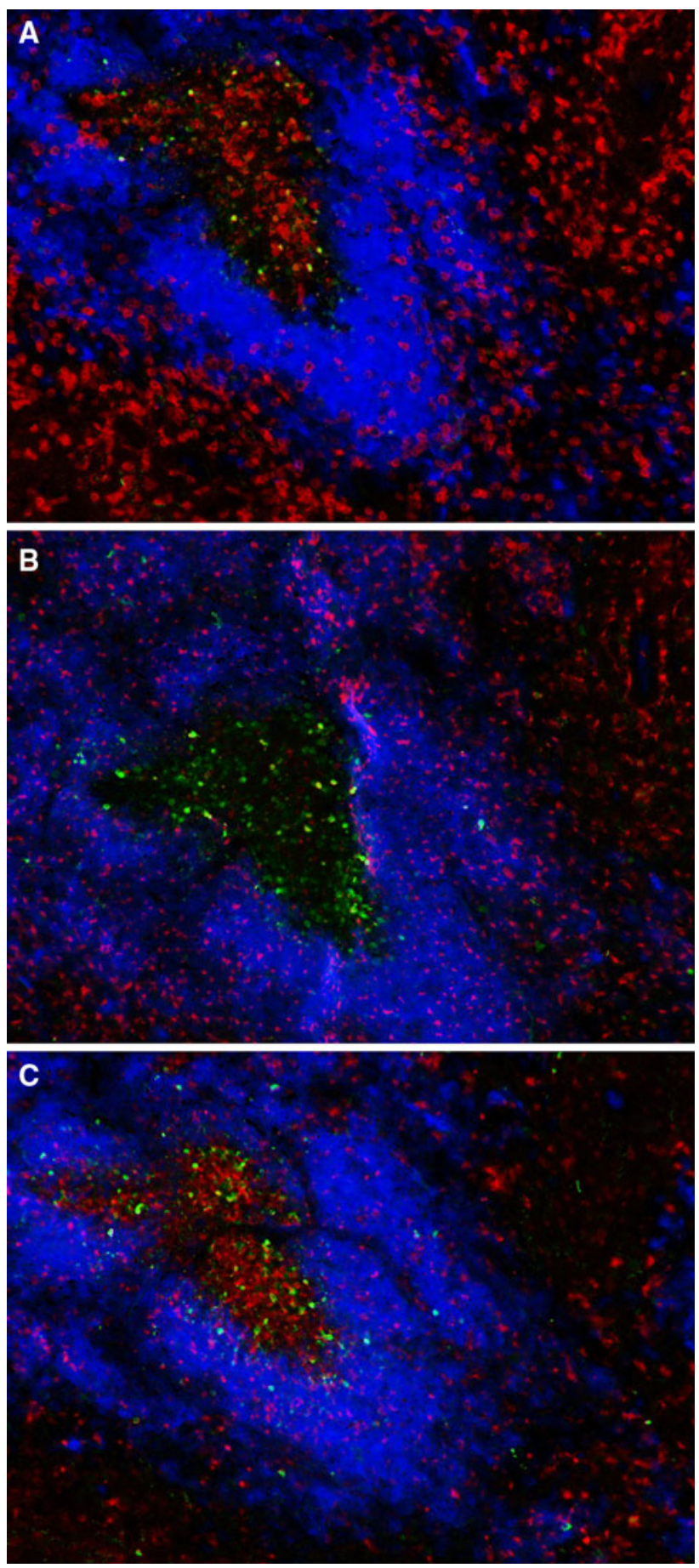

Fig. 3 Triple staining of CGD granuloma in lung tissue. a (left): neutrophils (MPO; red), IDO (blue), activated caspase 3 (apoptosis, green); $\mathbf{b}$ (middle) as in A for macrophages $(\mathrm{CD} 68 ;$ red $)$, $\mathbf{c}($ right $)$ as in a for $\mathrm{T}$ cells (CD3; in red)

from patients with sarcoidosis and tuberculosis (Lutter, van der Loos, unpublished). Since IDO activity induces apoptosis, apoptotic cells in the vicinity of IDO expression in CGD tissue can be taken as an indicator of IDO activity. Indeed, marked numbers of apoptotic (active caspase-3 
positive) cells were found, predominantly in the center and border of the granulomata and consisting of neutrophils, $\mathrm{T}$ cells, and macrophages. These findings-taken together with the findings on L-kynurenine and IDO activity in CGD patients recently published by Malech et al. [28]—suggest that the general activity may be normal, while locally induced IDO activity may still be present in the affected tissues. It is unclear whether this markedly increased yet localized IDO activity in CGD patients directly contributes to the clinical manifestations of hyperinflammation in CGD. In a previous study by one of us, it was shown that IDO activity may lead to the increased production of inflammatory mediators by airway epithelial cells, which will lead to an exaggerated inflammatory reaction [29]. In an experimental pneumonia model, a similarly IDO-mediated enhanced production of both TNF- $\alpha$ and IL- 10 was found [30]. IL-10 is known to inhibit neutrophil function and thus contribute to the increased bacterial load observed in this lung model. Together, this could indicate that an enhanced IDO activity in granulomata may enhance the recruitment of inflammatory cells and at the same time prevent their functioning, which may lead to a prolongation of the inflammatory response.

\section{T lymphocytes in inflammation and neutrophilia}

Discoveries made over the past two decades have markedly changed the way we assume immunological processes are being regulated. Not the least of these was the identification and cloning of several new cytokines, including IL-17 [31]. These discoveries provided the impetus to explore outside the Thelper 1 (Th1)-Th2 cell paradigm in search of answers to explain the effector $\mathrm{T}$ cell responses that occur independently of known Th1 and Th2 cell-signaling pathways. It was clear that a strong $\mathrm{T}$ cell-dependent response can occur even in the absence of the Th1 cell-promoting factors IFN- $\gamma$, signal transducer and activator of transcription-1 (STAT1) and STAT4 or the Th2 cell promoting factors IL-4, STAT6 and GATA-binding protein-3 (GATA3). Through the study of the role of IL-23 in autoimmunity, it was discovered that an alternative $\mathrm{T}$ cell subset can promote chronic inflammation and tissue damage [32]. The Th17 cell was identified as a cell, in which IL-6-STAT3 activation of the transcriptional regulator retinoic acid receptor-related orphan receptor- $\gamma \mathrm{t}(\mathrm{ROR} \gamma \mathrm{t})$ controls the lineage fate of IL-17, IL-21-, and IL-22-producing $\mathrm{T}$ cells (known as Th17 cells), that are highly responsive to IL-1-receptor-I (IL-1R1) and IL-23R signaling [32].

The adaptive Th17 cell pathway was inadequate to explain the early IL-17-mediated immune responses that have crucial roles during stress responses and host defense.
The IL-17-mediated immune pathway is induced within hours following epithelial cell injury or activation of pattern-recognition receptors (PRRs), which is not enough time for the development of Th17 cells. IL-17 produced within 4-8 $\mathrm{h}$ after microbial infection was shown to enhance neutrophil chemotaxis by promoting IL-6, G-CSF, and CXC-chemokine ligand-8 (CXCL8; also known as IL-8) production and to trigger rapid, nonspecific immunity to infectious agents [33].

A hallmark of innate immunity is its rapid response to pathogens. Innate IL-17-producing cells can induce epithelial cell secretion of granulopoietic factors such as G-CSF, which recruit large numbers of neutrophils crucial for effective and rapid control of bacterial and fungal pathogens. IL-17 also synergizes with other cytokines, such as IL-1, IL-6, and TNF- $\alpha$ that promote activation of tissue infiltrating neutrophils to effectively eliminate extracellular pathogens, such as Klebsiella pneumoniae, Staphylococcus aureus, and Candida albicans. Several innate cell subsets could cooperate to promote this immediate IL-17-mediated response. In the lung, skin, liver, and gut, the $\gamma \delta \mathrm{T}$ cell subset has been implicated as a primary source of early IL17 production in several in vivo models of infection. Initial studies looked at extracellular pathogens that target the lungs, such as K. pneumoniae, and showed that IL-23 was a main stimulator of innate IL-17 production [34].

It is important to note that innate IL-17 populations not only interact with pathogens during infection but also interact with the commensal flora to maintain mucosal homeostasis. IL-17 also has an important role in maintaining mucosal barrier integrity both during homeostasis and pathogenic insults. One way IL-17 can preserve tissue integrity is by enhancing synthesis of tight junction proteins, such as claudin. These tight-junction proteins form interconnecting ultrastructures between epithelial cells to keep out gut luminal contents and commensal organisms. Another mechanism for the protective effects of IL-17 is the induction of antimicrobial agents such as $\beta$-defensins, regenerating $(\mathrm{ReG})$ proteins, $\mathrm{S} 100$ proteins, lipocalins, and lactoferrins. These microbicidal agents are predominantly produced by epithelial cells, as well as neutrophils and macrophages that constitutively express IL-17R. It is notable that IL-17 often works cooperatively with IL-22. In the airways, IL-17 and IL-22 have been shown to work together to promote the secretion of human $\beta$-defensin- 2 , $\beta$-defensin- 3 and calgranulin by bronchial epithelial cells, essential for the killing of bacterial and fungal pathogens [35], a defect that may explain the recurrent skin and lung infections in the autosomal-dominant Hyper-IgE syndrome, as caused by mutations in STAT3.

Also in the gut mucosa, IL-17 and IL-22 may have synergistic effects on the induction of antimicrobial proteins such as $\operatorname{ReG} 3 \gamma$ by gastrointestinal epithelial cells 
known as Paneth cells, which have an important role in the control of pathogens and limits dissemination of commensal bacteria that could penetrate a disrupted epithelial barrier. These innate and adaptive memory immune cells can be assumed to act in concert to produce a basal level of IL-17 and IL-22, which then maintain a constitutive level of antimicrobial proteins [36].

\section{IL-17-mediated activity during infections in CGD}

IL-17 augmented inflammation, but, paradoxically, impaired neutrophil antifungal host defense in mice [37]. As mentioned earlier, Romani et al. demonstrated that IDOmediated L-tryptophan metabolism along the kynurenine pathway is defective in CGD mice. As a consequence, unrestrained $\gamma \delta \mathrm{T}$ cell and $\alpha \beta$ Th17 expansion, defective regulatory Treg activity, and acute inflammatory lung injury leading to mortality occurred in CGD mice when challenged with intratracheal Aspergillus fumigatus [23]. Although complete protection from invasive fungal disease and reversal of the hyperinflammatory phenotype were achieved by recombinant IFN- $\gamma$ and administration of a natural L-kynurenine distal to the IDO blockade was suggested, beneficial effects in this infection model were also induced by IL-17 neutralization or depletion of $\gamma \delta$ T cells (which produce IL-17) in CGD mice [23, 38]. Similar to Aspergillus challenge, intratracheal zymosan (a sterile fungal cell wall constituent that ligates Toll-like receptor 2 and dectin-1), caused dramatically augmented lung inflammation and IL-17 production and diminished Treg responses in CGD compared to wild-type mice, emphasizing the intrinsic regulatory role of the NADPH oxidase on inflammation [39]. George-Chandy et al. recently showed that $\mathrm{gp} 91^{\text {phox }}$-negative dendritic cells (DCs) enhance induction of both Th17 and Th1 responses in vitro compared to wild-type DCs [40]. T cell development was dependent exclusively on the NADPH oxidase status of the activating DCs rather than the responding $\mathrm{T}$ cells. To date, we did not detect a defect in Th17 development in CGD patients, making alternative explanations well possible.

\section{Inflammatory and regulatory $T$ cells}

Tregs and IL-17-producing $\mathrm{T}$ cells mediate opposing responses. IL-17 stimulates production of G-CSF, GM$\mathrm{CSF}$, TNF- $\alpha$, and chemokines that regulate myelopoiesis and neutrophil recruitment to inflammatory sites. The IL23/IL-17 axis (IL-23 expands Th17 cells) mediates several experimental autoimmune disorders, including colitis, collagen-induced arthritis, and experimental autoimmune encephalomyelitis, and is a promising target for drug development. T cells producing IL-17, which is known to drive chronic inflammation, are held in check by regulatory $\mathrm{T}$ cells. Although a potential role of IL-17-producing cells will very well be possible, this mechanism requires further confirmation in human CGD patients. On the other hand, Montagnoli et al. [38] previously showed that naturally occurring Tregs are recruited early in the inflammatory response to Aspergillus in wild-type mice, and are capable of suppressing inflammation.

Apart from IDO activity and localization of Th17 reactivity, a regulatory defect in the Treg-mediated control of the adaptive immune system may be present in CGD. The role of Tregs in the exaggerated innate immune reactivity loop in CGD was suggested by previous studies in mice and rats with mutant Ncfl alleles (encoding $\mathrm{p} 47^{\mathrm{phox}}$ ) associated with defective ROS production. Due to a less functional NADPH oxidase complex, these animals are more susceptible to develop autoimmune diseases as compared to littermates with normal ROS production [41, 42]. This is in line with the observation that patients with CGD who are unable to produce ROS have a higher incidence of autoimmune diseases such as granulomatous colitis or Crohn's-like disease (CD), rheumatoid arthritis (RA), or systemic lupus erythematosus (SLE) [43, 44].

In the rat model for CGD, the $\mathrm{T}$ cells were responsible for mediating the higher susceptibility to pristane-induced arthritis [41, 45]. However, $T$ cells themselves do not express $\mathrm{p} 47^{\text {phox }}$ and do not produce ROS via NADPH oxidase [46]. Instead, the antigen-presenting cells were involved in aberrant adaptive immune reactivity under these conditions. Macrophages are far more efficient in producing ROS as compared to B cells and dendritic cells (DC) [47]. A transgenic mouse was developed that expressed functional $\mathrm{p} 47^{\text {phox }}$ in macrophages only, on a $\mathrm{p} 47^{\text {phox }}$-mutated background. These mice were equally protected against collagen-induced arthritis as wild-type littermates, indicating that macrophage-derived ROS are sufficient to prevent the induction of unwanted $\mathrm{T}$ cell reactivity [47].

Regulatory T cells (Tregs) can suppress activation and proliferation of effector $\mathrm{T}$ cells and thereby diminish most immune responses. Autoimmunity can therefore be the result of a defective Treg system [48] and successful treatment of autoimmune disease with Tregs has been reported in mouse models $[49,50]$. Reasoning along these lines, Treg induction via ROS can be mediated via macrophages, as was reported before [51]. In collaboration, Keldeman et al. indeed observed that such a mechanism of ROS-dependent Treg induction seems to be relevant to CGD. Macrophage-derived ROS could induce Tregs under normal conditions. In contrast, macrophages from CGD patients were significantly less efficient in inducing Tregs (Keldeman et al. PNAS 2011). Thus, macrophages 
producing ROS help induce Tregs for proper immune regulation, a regulatory loop that seems to be impaired in CGD. Previously it has been found that $\mathrm{T}$ cell suppression by Tregs induced by anti-inflammatory macrophages is dependent on membrane-bound TGF- $\beta$ [51]. A role for ROS to activate TGF- $\beta$ was suggested before $[52,53]$, and this may subsequently determine the induction of Tregs.

In sum, when macrophages prevent $\mathrm{T}$ cell reactivity by producing ROS, the activation signal needs to overcome a certain threshold level for $\mathrm{T}$ cell activation and this failsafe mechanism may thus prevent unwanted inflammation and autoimmunity.

\section{Conclusions}

To date, the abundant presence of results in experimental mouse models as well as in human CGD patients indicate that the NADPH oxidase complex is able to restrain inflammation by modulating redox-sensitive innate immune pathways. When challenged with either intratracheal zymosan or LPS, NADPH oxidase-deficient (CGD p $47^{\text {phox }}$ and $\mathrm{gp} 91^{\text {phox }}$-deficient mice develop exaggerated and progressive lung inflammation, which is paralleled by augmented NF- $\kappa$ B activation and elevated downstream proinflammatory cytokines (TNF- $\alpha$, IL-17, and G-CSF) in comparison to wild-type mice [39]. Replacement of functional NADPH oxidase in bone marrow-derived cells restored the normal lung inflammatory response in experimental models. These recent studies further demonstrated that in the absence of a functional NADPH oxidase system, the yeast capsular zymosan particles fail to activate Nrf2, a key redox-sensitive anti-inflammatory regulator. A small chemical compound, the triterpenoid CDDO-Im, activated Nrf2 independently of NADPH oxidase and reduced the zymosan-induced lung inflammation in CGD mice. Consistent with these findings, zymosan-treated peripheral blood mononuclear cells from human X-linked CGD patients also showed impaired Nrf2 activity and increased NF- $\kappa$ B activation.

Whether these two observations in mice and human macrophages are directly linked and to which extent these data relate to $\mathrm{T}$ cell-mediated regulation of the hyperinflammatory reactivity in CGD patients as discussed above, remains to be studied in greater detail. Apart from IL-17, the role of TGF- $\beta$ induction, activation and downregulation may be relevant to the outcome of inflammation and subsequent risk of proceeding tissue fibrosis, as can be observed in chronic disease in CGD patients.

Together these studies support a model in which NADPH oxidase-dependent, redox-mediated signaling is critical for termination of lung inflammation and suggest new potential therapeutic targets for CGD.

Open Access This article is distributed under the terms of the Creative Commons Attribution Noncommercial License which permits any noncommercial use, distribution, and reproduction in any medium, provided the original author(s) and source are credited.

\section{References}

1. Johnston RB Jr (2001) Clinical aspects of chronic granulomatous disease. Curr Opin Hematol 8:17-22

2. Segal BH, Leto TL, Gallin JI, Malech HL, Holland SM (2000) Genetic, biochemical, and clinical features of chronic granulomatous disease. Rev Mol Med 79:170-200

3. van den Berg JM, van Koppen E, Ahlin A, Belohradsky BH, Bernatowska E, Corbeel L, Espanol T, Fischer A, KurenkoDeptuch M, Mouy R, Petropoulou T, Roesler J, Seger R, Stasia MJ, Valerius NH, Weening RS, Wolach B, Roos D, Kuijpers TW (2009) Chronic granulomatous disease: the European experience. PLoS One 4:e5234

4. Egen JG, Rothfuchs AG, Feng CG, Winter N, Sher A, Germain RN (2008) Macrophage and T cell dynamics during the development and disintegration of mycobacterial granulomas. Immunity 28:271-284

5. Matute JD, Arias AA, Wright NA, Wrobel I, Waterhouse CC, Li XJ, Marchal CC, Stull ND, Lewis DB, Steele M, Kellner JD, Yu W, Meroueh SO, Nauseef WM, Dinauer MC (2009) A new genetic subgroup of chronic granulomatous disease with autosomal recessive mutations in p40 phox and selective defects in neutrophil NADPH oxidase activity. Blood 114:3309-3315

6. Ambruso DR, Knall C, Abell AN, Panepinto J, Kurkchubasche A, Thurman G, Gonzalez-Aller C, Hiester A, de Boer M, Harbeck RJ, Oyer R, Johnson GL, Roos D (2000) Human neutrophil immunodeficiency syndrome is associated with an inhibitory Rac2 mutation. Proc Natl Acad Sci USA 97:4654-4659

7. Bokoch GM, Diebold BA (2002) Current molecular models for NADPH oxidase regulation by Rac GTPase. Blood 100:26922696

8. Gallin JI, Buescher ES (1983) Abnormal regulation of inflammatory skin responses in male patients with chronic granulomatous disease. Inflammation 7:227-232

9. Morgenstern DE, Gifford MA, Li LL, Doerschuk CM, Dinauer MC (1997) Absence of respiratory burst in X-linked chronic granulomatous disease mice leads to abnormalities in both host defense and inflammatory response to Aspergillus fumigatus. J Exp Med 185:207-218

10. Chang YC, Segal BH, Holland SM, Miller GF, Kwon-Chung KJ (1998) Virulence of catalase-deficient Aspergillus nidulans in $\mathrm{p} 47(\mathrm{phox})^{-/-}$mice. Implications for fungal pathogenicity and host defense in chronic granulomatous disease. J Clin Invest 101:1843-1850

11. Warris A, Netea MG, Wang JE, Gaustad P, Kullberg BJ, Verweij PE, Abrahamsen TG (2003) Cytokine release in healthy donors and patients with chronic granulomatous disease upon stimulation with Aspergillus fumigatus. Scand J Infect Dis 35:482-487

12. Hatanaka E, Carvalho BT, Condino-Neto A, Campa A (2004) Hyperresponsiveness of neutrophils from gp 91phox-deficient patients to lipopolysaccharide and serum amyloid A. Immunol Lett 94:43-46

13. Bylund J, MacDonald KL, Brown KL, Mydel P, Collins LV, Hancock RE, Speert DP (2007) Enhanced inflammatory responses of chronic granulomatous disease leukocytes involve 
ROS-independent activation of NF-kappa B. Eur J Immunol 37:1087-1096

14. van de Veerdonk FL, Smeekens SP, Joosten LA, Kullberg BJ, Dinarello CA, van der Meer JW, Netea MG (2010) Reactive oxygen species-independent activation of the IL-1beta inflammasome in cells from patients with chronic granulomatous disease. Proc Natl Acad Sci USA 107:3030-3033

15. van Bruggen R, Köker MY, Jansen M, van Houdt M, Roos D, Kuijpers TW, van den Berg TK (2010) Human NLRP3 inflammasome activation is Nox1-4 independent. Blood 115:53985400

16. Meissner F, Seger RA, Moshous D, Fischer A, Reichenbach J, Zychlinsky A (2010) Inflammasome activation in NADPH oxidase defective mononuclear phagocytes from patients with chronic granulomatous disease. Blood 116:1570-1573

17. Popov A, Abdullah Z, Wickenhauser C, Saric T, Driesen J, Hanisch FG, Domann E, Raven EL, Dehus O, Hermann C, Eggle D, Debey S, Chakraborty T, Kronke M, Utermohlen O, Schultze JL (2006) Indoleamine 2, 3-dioxygenase-expressing dendritic cells form suppurative granulomas following Listeria monocytogenes infection. J Clin Invest 116:3160-3170

18. Grohmann U, Fallarino F, Puccetti P (2003) Tolerance, DCs and tryptophan: much ado about IDO. Trends Immunol 24:242-248

19. Pfefferkorn ER, Eckel M, Rebhun S (1986) Interferon-gamma suppresses the growth of Toxoplasma gondii in human fibroblasts through starvation for tryptophan. Mol Biochem Parasitol 20:215-224

20. Adams O, Besken K, Oberdorfer C, MacKenzie CR, Russing D, Daubener W (2004) Inhibition of human herpes simplex virus type 2 by interferon gamma and tumor necrosis factor alpha is mediated by indoleamine 2, 3-dioxygenase. Microbes Infect 6:806-812

21. Lee GK, Park HJ, Macleod M, Chandler P, Munn DH, Mellor AL (2002) Tryptophan deprivation sensitizes activated T cells to apoptosis prior to cell division. Immunology 107:452-460

22. Munn DH, Shafizadeh E, Attwood JT, Bondarev I, Pashine A, Mellor AL (1999) Inhibition of T cell proliferation by macrophage tryptophan catabolism. J Exp Med 189:1363-1372

23. Romani L, Fallarino F, De Luca A, Montagnoli C, D'Angelo C, Zelante T, Vacca C, Bistoni F, Fioretti MC, Grohmann U, Segal BH, Puccetti P (2008) Defective tryptophan catabolism underlies inflammation in mouse chronic granulomatous disease. Nature 451:211-215

24. Siddiqui S, Anderson VL, Hilligoss DM, Abinun M, Kuijpers TW, Masur H, Witebsky FG, Shea YR, Gallin JI, Malech HL, Holland SM (2007) Fulminant mulch pneumonitis: an emergency presentation of chronic granulomatous disease. Clin Infect Dis 45:673-681

25. Murray HW, Szuro-Sudol A, Wellner D, Oca MJ, Granger AM, Libby DM, Rothermel CD, Rubin BY (1989) Role of tryptophan degradation in respiratory burst-independent antimicrobial activity of gamma interferon-stimulated human macrophages. Infect Immun 57:845-849

26. Vottero E, Mitchell DA, Page MJ, MacGillivray RT, Sadowski IJ, Roberge M, Mauk AG (2006) Cytochrome b(5) is a major reductant in vivo of human indoleamine 2, 3-dioxygenase expressed in yeast. FEBS Lett 580:2265-2268

27. Ozaki Y, Nichol CA, Duch DS (1987) Utilization of dihydroflavin mononucleotide and superoxide anion for the decyclization of L-tryptophan by murine epididymal indoleamine 2, 3-dioxygenase. Arch Biochem Biophys 257:207-216

28. De Ravin SS, Zarember KA, Long-Priel D, Chan KC, Fox SD, Gallin JI, Kuhns DB, Malech HL (2010) Tryptophan/kynurenine metabolism in human leukocytes is independent of superoxide and is fully maintained in chronic granulomatous disease. Blood 116:1755-1760
29. Van Wissen M, Snoek M, Smids B, Jansen HM, Lutter R (2002) IFN- $\gamma$ amplifies IL- 6 and IL- 8 responses by airway epithelial-like cells via indoleamine 2, 3-dioxygenase. J Immunol 169:70397044

30. van der Sluijs KF, Nijhuis M, Levels JH, Florquin S, Mellor AL, Jansen HM, van der Poll T, Lutter R (2006) Influenza-induced expression of indoleamine 2, 3-dioxygenase enhances interleukin-10 production and bacterial outgrowth during secondary pneumococcal pneumonia. J Infect Dis 193:214-222

31. Korn T, Bettelli E, Oukka M, Kuchroo VK (2009) IL-17 and Th17 cells. Annu Rev Immunol 27:485-517

32. Iwakura Y, Nakae S, Saijo S, Ishigame H (2008) The roles of IL-17A in inflammatory immune responses and host defense against pathogens. Immunol Rev 226:57-79

33. Happel KI, Dubin PJ, Zheng M, Ghilardi N, Lockhart C, Quinton LJ, Odden AR, Shellito JE, Bagby GJ, Nelson S, Kolls JK (2005) Divergent roles of IL-23 and IL-12 in host defense against Klebsiella pneumoniae. J Exp Med 202:761-769

34. Cua DJ, Tato CM (2010) Innate IL-17-producing cells: the sentinels of the immune system. Nat Rev Immunol 10:479-489

35. Minegishi Y, Saito Y, Nagasawa M, Takada H, Hara T, Tsuchiya S, Agematsu K, Yamada M, Kawamura N, Ariga T, Tsuge I, Karasuyama H (2009) Molecular explanation for the contradiction between systemic Th17 defect and localized bacterial infection in hyper-IgE syndrome. J Exp Med 206:1291-1301

36. Zheng Y, Valdez PA, Danilenko DM, Hu Y, Sa SM, Gong Q, Abbas AR, Modrusan Z, Ghilardi N, de Sauvage FJ, Ouyang W (2008) Interleukin-22 mediates early host defense against attaching and effacing bacterial pathogens. Nat Med 14:282-289

37. Zelante T, De Luca A, Bonifazi P, Montagnoli C, Bozza S, Moretti S, Belladonna ML, Vacca C, Conte C, Mosci P, Bistoni F, Puccetti P, Kastelein RA, Kopf M, Romani L (2007) IL-23 and the Th17 pathway promote inflammation and impair antifungal immune resistance. Eur J Immunol 37:2695-2706

38. Montagnoli C, Fallarino F, Gaziano R, Bozza S, Bellocchio S, Zelante T, Kurup WP, Pitzurra L, Puccetti P, Romani L (2006) Immunity and tolerance to Aspergillus involve functionally distinct regulatory $\mathrm{T}$ cells and tryptophan catabolism. J Immunol 176:1712-1723

39. Segal BH, Han W, Bushey JJ, Joo M, Bhatti Z, Feminella J, Dennis CG, Vethanayagam RR, Yull FE, Capitano M, Wallace PK, Minderman H, Christman JW, Sporn MB, Chan J, Vinh DC, Holland SM, Romani LR, Gaffen SL, Freeman ML, Blackwell TS (2010) NADPH oxidase limits innate immune responses in the lungs in mice. PLoS One 5:e9631

40. George-Chandy A, Nordstrom I, Nygren E, Jonsson IM, Postigo J, Collins LV, Eriksson K (2008) Th17 development and autoimmune arthritis in the absence of reactive oxygen species. Eur J Immunol 38:1118-1126

41. Olofsson P, Holmberg J, Tordsson J, Lu S, Akerstrom B, Holmdahl R (2003) Positional identification of Ncf1 as a gene that regulates arthritis severity in rats. Nat Genet 33:25-32

42. Hultqvist M, Olofsson P, Holmberg J, Backstrom BT, Tordsson J, Holmdahl R (2004) Enhanced autoimmunity, arthritis, and encephalomyelitis in mice with a reduced oxidative burst due to a mutation in the Ncf1 gene. Proc Natl Acad Sci USA 101:1264612651

43. Rosenzweig SD (2008) Inflammatory manifestations in chronic granulomatous disease (CGD). J Clin Immunol 28(Suppl 1):S67S72

44. Schappi MG, Jaquet V, Belli DC, Krause KH (2008) Hyperinflammation in chronic granulomatous disease and antiinflammatory role of the phagocyte NADPH oxidase. Semin Immunopathol 30:255-271

45. Holmberg J, Tuncel J, Yamada H, Lu S, Olofsson P, Holmdahl R (2006) Pristane, a non-antigenic adjuvant, induces MHC class 
II-restricted, arthritogenic $\mathrm{T}$ cells in the rat. $\mathrm{J}$ Immunol 176:1172-1179

46. Geldeman KA, Hultqvist M, Holmberg J, Olofsson P, Holmdahl $\mathrm{R}$ (2006) $\mathrm{T}$ cell surface redox levels determine $\mathrm{T}$ cell reactivity and arthritis susceptibility. Proc Natl Acad Sci USA 103:12831-12836

47. Geldeman KA, Hultqvist M, Pizzolla A, Zhao M, Nandakumar KS, Mattsson R, Holmdahl R (2007) Macrophages suppress T cell responses and arthritis development in mice by producing reactive oxygen species. J Clin Invest 117:3020-3028

48. Adeegbe D, Matsutani T, Yang J, Altman NH, Malek TR (2010) $\mathrm{CD} 4+\mathrm{CD} 25+$ Foxp $3+\mathrm{T}$ regulatory cells with limited TCR diversity in control of autoimmunity. J Immunol 184:56-66

49. Bluestone JA, Tang Q (2004) Therapeutic vaccination using CD4 + CD25 + antigen-specific regulatory T cells. Proc Natl Acad Sci USA 101(Suppl 2):14622-14626

50. Tang Q, Henriksen KJ, Bi M, Finger EB, Szot G, Ye J, Masteller EL, McDevitt H, Bonyhadi M, Bluestone JA (2004) In vitro- expanded antigen-specific regulatory $\mathrm{T}$ cells suppress autoimmune diabetes. J Exp Med 199:1455-1465

51. Savage ND, de Boer T, Walburg KV, Joosten SA, van Meijgaarden K, Geluk A, Ottenhoff TH (2008) Human anti-inflammatory macrophages induce Foxp3 + GITR + CD25 + regulatory T cells, which suppress via membrane-bound TGFbeta-1. J Immunol 181:2220-2226

52. Kraaij MD, Savage ND, van der Kooij SW, Koekkoek K, Wang J, van den Berg JM, Ottenhoff TH, Kuijpers TW, Holmdahl R, van Kooten C, Gelderman KA (2010) Induction of regulatory T cells by macrophages is dependent on production of reactive oxygen species. Proc Natl Acad Sci USA 107:17686-17691

53. Pociask DA, Sime PJ, Brody AR (2004) Asbestos-derived reactive oxygen species activate TGF-beta1. Lab Invest 84:10131023 